\title{
Toward an Empowering Pedagogy: Is There Room for Critical Pedagogy in Educational System of Iran?
}

\author{
Parvin Safari \\ Teacher Education College of Yazd, Iran \\ Email: psafari2009@gmail.com \\ Mohammad R. Pourhashemi \\ Teacher Education College of Yazd, Iran \\ Email: pourhashemi_m@yahoo.com
}

\begin{abstract}
Critical pedagogy $(\mathrm{CP})$ as an alternative approach to ELT with the aim of social action, educational change, and the betterment of society attempting to empower learners to critically question, reflect, and act upon inequitable, undemocratic, oppressive institutions and social relations, has not long been introduced, studied, or researched in Iranian educational contexts. While in some countries over the past two decades, there exists a growing body of researches and studies challenging and addressing different aspects of this approach, in Iran much less has been reported on the respective issue so that it has remained in its primitive phases of prosperity. In deed, this qualitative study intends to firstly present an overview concerning historical background as well as core concepts of CP. Then, it will explore and discuss the problems and constraints regarding its applicability in educational system of Iran.
\end{abstract}

Index Terms-critical pedagogy, ELT, educational change, social relations, social action

\section{INTRODUCTION}

Over the last two decades, language teaching profession experienced an unequivocally critical shift. In Kumaravadivelu's (2006) terms, it can probably be considered as one of the last academic principles in the field of humanities and social sciences to go critic. In his words, this critical turn is simply concerned with connecting word to the world and the recognition of language as an ideology, not just as a system. It is also concerned with extending the educational space to the social, cultural, and political dynamics of language use and the realization that language learning and teaching are more than learning and teaching language. It is also about creating the cultural forms and knowledge that give meaning to teachers' and learners' lived experiences.

Within a decade or so, the trend moved so fast that critical pedagogy along its themes emerged on the scene. The themes include discourse analysis (Fairclough, 1995), language and identity (Norton, 1997), critical approaches to TESOL (Pennycook, 1999), teaching for academic purposes (Benesch, 2001), language in development (Markee, 2002), and also gender and language education (Davis\&Skilton-Sylvester, 2004). In fact, critical pedagogy as a postmethod approach which is the offspring of this pedagogical revolution according to Kincheloe (2005) suggests novel ways of looking at classroom practices, aiming at humanizing and empowering learners to be emancipated through transforming relations of power which are oppressive. As Benesch (2001) puts it, critical pedagogy is used as a means of linking the linguistic texts, sociopolitical context, and the academic content with the larger community for the purpose of changing classroom input and interaction into effective instruments of transformation.

Regarding the significance of social change, Noroozisiam and Soozandefar (2012) state that when we focus on social transformation, education proves to be considered as a political issue in the need of being politically dealt with. This kind of education influences everything including curriculum, materials, teachers, and learners. In deed, critical pedagogy creates a healthy non-alienating classroom-social relationship with no dominant policy overhanging in the minds of individuals. Therefore, due to the fact that language learning classrooms are far removed from historical and political conditions (Okazaki, 2005), many researchers advocate the inclusion of $\mathrm{CP}$ at the heart of language classrooms with the purpose of examining the sociohistorical and political aspects of language learning (Benesch, 2001; Canagarajah, 1999, 2002; Morgan, 1998; Norton, 1997; Norton\&Toohey, 2004; Pennycook, 1999, 2001; Ramanthan, 2002).

In addition to what was mentioned above, failures and successes of an educational system depend on the people's linguistic and socio-cultural interaction which are under the influence of dominant ideology, institutional practice and social relations (Heras, 1999). Critical pedagogy thus endeavors to enhance the students' critical consciousness to challenge the domination and subjugation that may distort and constraint their modes of thinking and acting (Sadeghi \& 
Ketabi, 2009). Critical pedagogy deals in fact with considering the socioeconomic and political inequities and injustices in the society which are oppressive and undemocratic. Its main occupation is to critically prepare students to interrogate and act upon social inequalities through challenging the status quo, deep-seated knowledge and taken-for-granted assumptions transferred by means of schools to students. This aim can not be achieved if language learning is taken as a mere acquisition of language skills and communicative competence without any consideration of the cultural and sociopolitical context in which it occurs.

\section{LITERATURE REVIEW: HISTORY \& KEY CONCEPTS}

Critical pedagogy as an alternative approach to language teaching and learning was historically perceived to be one realization of critical theory of Frankfurt school established in 1923 (Gur-ze'ev, Kincheloe, \& Lather, 1998; Mclaren, 2003). In deed, Marx was considered to be as one of the prominent figures whose ideas and views greatly influenced the critical theoretical tradition developed by Frankfurt school. Marx believed that the essential societal problem was socioeconomic inequality. In other words, social justice depends on economic conditions (Eisner, 2002).

The first critical theorists of Frankfurt school who adopted and embraced some of Marx's views related to schools and education were Marx, Horkheimer, Theodor, Adomo and most significantly Herbert Marcuse. They all argued that schools promoted dependency, a hierarchical understanding of power, a distorted view of history, and other taken-forgranted truths that in turn impeded social change and transformation (Eisner, 2002).

The concept of critical pedagogy is actually associated with the work of scholars including Freire (1970), Giroux (1992), Luke (1988), Mclaren (1989), and Simon (1992) who focused their efforts on examining and understanding the roles that schools play in transmitting certain messages about political, economic and social life. They all believed that critical pedagogy will allow educators to realize the possibilities of democratic social values within their classrooms (Kincheloe, 2004). Among these scholars, the pioneering figure associated with Latin American movement is Paulo Freire who is commonly known as an inaugural philosopher and theorist of critical pedagogy (Mclaren, 2000). Freire's pedagogy of the oppressed (1970) which offered a general theory of knowledge was the result of his personal experiences with the poor and impoverished peasants in Brazil that compelled him to develop ideals and practices which served to improve the lives of the marginalized. In fact, pedagogy of the oppressed asserted that modern educational institutions and schools were dehumanizing and simply reproduced status quo. This book actually inspired those radicals who then entered the teaching English profession and remained as a point of common reference for critical pedagogues (Palmer \& Emmons, 2004).

Freire believed that schools would be the impediments to the education of the poor, so he sought to find strategies for students to intervene in dehumanizing process. Based on Freire's views (1970), this educative process was called libratory action or praxis. Accordingly, people are required to engage in praxis that incorporates theory, action, and reflection toward social change and justice. The key concepts introduced by Freire can still be found in much literature, the concepts such as the" banking theory of education," "concientization," "dialogical method," and "transformative education," among others. In the "banking theory of education," deposits of knowledge and predetermined facts are transferred from the teacher as the authority to the students as the passive receivers who have no chance of challenging, questioning, and reconstructing this practically irrelevant and intact knowledge.

An alternative to this drab and soulless system is "problem posing" or "dialogical theory of education," which is dialogical, critical, and reflective in nature. Based on this view of education, teachers' and learners' personal experiences in a non- hierarchical manner are shared that it subsequently leads to their cognitive and sociopolitical development. Through non-authoritarian social relationships, dialogue and sharing every day experiences which are connected to learners' marginalization, learners can critically come to a realization of main reasons for their oppression and this is what was named as "concientization". In this process, both teacher and learners become social agents of change through transformation in that learners become active critical citizens who speak out against social, economic, and political injustices being present both within and outside of schools. The teacher's role is not yet a technical labor but as a transformative intellectual, or as an active and reflective scholar who, through the provision of dialogue and communication, tries to enable learners to question the meaning and nature of knowledge and to peel away the hidden structures of reality.

The application of critical pedagogy and associated problems in educational system of Iran

In order to be satisfactorily implemented in ELT classrooms, any innovative approach encounters ups and downs in the process of development to reach to its burgeoning phase. Critical pedagogy as a new approach to language teaching has not long been introduced, studied, and researched in the educational settings of Iran. It is no exaggeration to say it is like a new born infant in the educational system of Iran, in need of maturity and development. Hence, lots of researches and studies are required to theoretically and practically indicate a vivid picture of its application in such an EFL context. Reviewing the literature of $\mathrm{CP}$, we can obviously see a wide range of researches across the globe attempting to theoretically and conceptually appreciate the different aspects of CP. However, much less has been reported to explore the practical considerations and problems of CP in EFL contexts like Iran.

Akbari (2008b), in this regard, asserts that despite its potential implications, however, the practical implications of $\mathrm{CP}$ have not been well appreciated and most of the references to the term have been restricted to its conceptual dimensions. Davari among others (2012) also points out that although the concept of CP has been around for some time 
in education, it has been recently explored in the practice of English Language Teaching. Thus, as Zacharias (2003) argues, in any study in the field of ELT, teachers and their beliefs play a central role in the delivery of language instruction. Accordingly, it seems to be necessary for the language teachers, professionals, practitioners, and planners of ELT to be aware of beliefs and attitudes they are operating from. This study, in fact, attempts to illuminate teachers' beliefs and attitudes concerning the problems, limitations, and hardships associated with the application of such a postmethod approach in educational system of Iran.

\section{Methodology}

\section{A. Participants}

12 English language teachers of both genders teaching English in different institutes and state schools in Yazd, Iran were randomly selected for this qualitative study. Through 16 hours of in-service classes held at Navid language institute of Yazd, they all got familiar with and gained fruitful insights related to theories, core principles and pedagogical practices implicating $\mathrm{CP}$.

\section{B. Instruments}

This qualitative study was conducted through the use of journal writing, observation and semi-structured interview in order to attain more valid data. Actually, the respective instruments purported to triangulate the data gained from the subjects. Then, the analysis of the derived data through the process of codification was meticulously done by the researcher with the assistance of another colleague. The analysis of the data vividly disclosed themes concerning $\mathrm{CP}$ and difficulties of its applicability in educational system of Iran.

\section{KEY FINDINGS}

In the pursuing parts, the different derived themes based on the analysis of the data illustrate and address the respective issue:

\section{A. Lack of Familiarity with the Approach}

How do we expect our teachers to be fully cognizant of such an innovative approach while there are a few Iranian universities in which $\mathrm{CP}$ as a subject is taught and researched? In deed, Iranian teachers seem to be in need of a breath of knowledge on $\mathrm{CP}$, good schemes of work, appropriate content and critical skills to enable them to teach according to the principles of CP (Aliakbari \& Allahmoradi, 2012). The best means through which Iranian teachers can gain awareness concerning the theoretical tenets and practical aspects of CP can be universities, institutes, pre-service and inservice classes. After all, the number of professors and lecturers whose academic syllabuses are based on this issue is relatively few.

The books and internet-based materials on the respective issue can also be of great assistance. But the availability of the materials can be another demand which needs to be carefully taken into account. This concern is rightly stated by a teacher as:

"To tell you the truth, I have heard about critical pedagogy so I am not familiar with it. I've read some books on methodology and learned a lot of techniques to apply in my language classes. Just recently a friend of mine introduced critical pedagogy to me very briefly. I liked to know more about it. Unfortunately not many teachers have enough information of it let alone applying it in their own language classes".

\section{B. Shortage of Fluent and Competent Teachers}

Critical approach demands highly fluent and competent teachers to naturally and spontaneously handle the challenging issues. Undoubtedly, not only $\mathrm{CP}$, but any other approach dealing with speaking, communication, dialogue, and interaction is also in urgent need of fluent and competent teachers. In Richard's (2011) terms, to teach effectively, a language teacher needs to possess language-specific competencies of which the ability to maintain fluent use of the target language is of great importance. Medgyes (2001) also asserts that a threshold proficiency level a teacher needs to have reached in the target language so as to be able to teach effectively in English. A teacher who has not reached this level of proficiency will be less likely to engage in improvisational teaching.

The most prevalent methods which are yet in vogue in educational system of Iran are GTM, ALM, and CLL. The first of these is widely used in state schools while the other two are the most favorites used in institutional settings. Unfortunately, due to the use of GTM in English classes of state schools and shadowing the banking education over Iranian educational contexts, teachers' fluency and competency have become infertile after so many years. Therefore, teachers are necessarily required to equip themselves with fluency and enhance their professional qualifications in English language so as to overcome the possible hardships and problems demanded by this approach. A teacher in his personal journal described this problem as:

"The most important skills that our students must have are reading comprehension, vocabulary, and grammar. The school textbooks are generally working on these skills. I do not need to speak English in my class all the time or discuss different issues at all. We have to translate all sentences to Persian and explain grammatical points in our students' mother tongue. This process has blocked our fluency. We, teachers, have mostly been fluent in English as 
university students. But after some years, we are not as we used to be regarding our fluency in English. I assume it is just due to lack of using language in class by us as teachers".

\section{Inaccessibility to the Critical Textbooks and Published Instructional Materials for both Teachers and Learners}

In fact, course book selection largely has an impact not only on the topics to be covered but also on the tasks and activities to be implemented in EFL classrooms. While suffering from poor ELT materials, critical pedagogy discourages the use of commercially produced textbooks and instructional materials (Rashidi\& Safari, 2011), since such materials alienate learners from realities of life, and eliminate creativity and responsibility from learners. However, one of the major criticisms that is directed toward CP is its practicality which can be enhanced through the provision and accessibility to the fully worked-out sample materials. With the aid of these materials, teachers can gain more insights and get familiar with the theories playing out in CP (Crooks, 2009). During the interview that I had with one of the teachers, she opined that:

"I have heard about critical pedagogy when participating in an EFL conference held in Yazd. One of the papers presented at this conference was on the issue of critical pedagogy. I tried to understand it but I didn't get it well. But I got interested in it. So I went to the bookstore to get some materials on it. Unfortunately even the book seller did not have any idea about that issue. I could not find any book on this topic at all".

In Iranian educational settings, both teachers and learners face with the paucity of respective materials which should be resolved in some way. In this regard, Aliakbari and Allahmoradi (2012) also state that due to the absence of standard textbooks on $\mathrm{CP}$, Iranian teachers have no time and instructional resources to integrate $\mathrm{CP}$ into their daily instruction. In educational system of Iran, not all teachers and learners have access to other resources like internet, rich libraries, magazines and newspapers to pay off the dearth of such materials. Accessibility to the instructional materials and course books including provocative topics is a major concern for English teachers. As one of them referred to this reality:

"As an English teacher who is going to implement critical pedagogy in my classes, I think our textbooks are devoid of any topics concerning the respective issue. So the best thing we can do is to choose some topics from magazines, newspapers and internet based on our students' interests and needs. But I think it's also so time consuming that with a low salary we receive monthly, no teacher is likely to do so".

In Akbari's (2008a) words, many of the available textbooks are sanitized and neutralized in order not to lose their market potential and in this process most of the topics for critical pedagogy are removed. In his terms, most of the topics one faces in commercially prepared textbooks deal with harmless issues which leave no room for social transformation and political awareness rising.

Actually, it is noteworthy to mention that both English textbooks used in ministry of education of Iran and most of the commercially prepared instructional course books available on the market include politically and socially neutral topics which bear no relationship with learners' social lives and immediate community. Also, most of the instructional materials and textbooks used in Iranian state schools are replete with the compilation of information and taken-forgranted knowledge which do not reflect any social issues related to learners' lives and experiences. In other words, they are on the basis of traditional banking education not aiming at developing learners' skills and awareness of the socioeconomic, political, and cultural issues existing in the contemporary society.

With respect to the importance of using challenging issues and activities which exploit learners' fruitful experiences related to the cultural and sociopolitical contexts, Akbari (2008b) nicely suggests that CP should 'connect word to world', so in order this connection to take place, marginalized learners must tackle world problems. It means they must learn to 'read world' before they 'read word' (Freire \& Macedo, 1999). In this regard, Noroozisiam and Soozandefar (2011) also state that individuals are required to connect the class to their community, and as a result to activate their minds so as to solve problems, and work for transformation; this is simply what "going beyond words" means.

In sum, it is suggested that textbooks should include topics which cultivate learners' understanding and awareness of the sociopolitical injustices and inequalities existing in the community and the ones which exploit learners' lived experiences related to the society and outside world. Therefore, instructional materials designers, curriculum developers and policy makers of education are expected to keep in mind that the materials should include provocative issues, hot topics and activities aiming at improving learners' abilities to come to an understanding of social, political, and cultural practices reflecting the wider community.

\section{Resistance of School Principals against any Innovative Approach}

According to Kanpol (1998), the authoritarian nature of schools is guided by control mechanisms, standardized curriculum, rigid rule structures, and top-down hierarchy. Within this authoritarian structure of education, obviously defined structural leaders and their subordinates constitute the ladder of control. This kind of school structure in deed deskills the teacher and robs her/him of the enthusiasm to proceed with their job creatively. Based on this argument, in this kind of system, for instance, division between principals and teachers, authority of principals over teachers, and that of teachers over learners in addition to the division of tasks and roles can clearly be examined.

It can be said that the educational system in Iran pursues a rigid rule structure with clearly pre-defined roles for principals, teachers and learners. Even when an innovative approach comes into play and all the private institutional 
settings are seriously armed to use their forces to adequately apply it, there would be severe and negative reactions on the part of state school principals.

In fact, this can be related to the same authoritarian nature of educational system in which principals exert their authority over teachers and other members. As an state school English teacher, I myself remember those unpleasant days that I wished to apply CLL in my own classes but I was so badly behaved that I preferred to leave it midway and continue the orthodox GTM as the favorite which fulfilled the immediate needs of principal and learners. This unfavorable reality has also been witnessed by other teachers, as one of them stated:

"Last year, I decided to avoid speaking Persian in my class. It was about less than a week that the school principal called me into her office. She asked me about the reason I spoke English in class. She said that a lot of students and even some parents had told her that many students did not understand anything in my class. At the end, the principal made me change my teaching method and avoid using English in my English class".

\section{E. Fossilized Unequal Power Relationship between Teacher and Students}

What makes Freire's (1970) pedagogical approach absolutely distinctive can be the assigned roles for both teacher and learners that are totally different from the traditional banking education. Based on the so-called 'banking model', the passive student is considered to be an empty account which needs to be filled with the knowledge that the teacher with the epistemological authority imparts to his or her discretion. In this process, the unequal distance and asymmetrical relations between teacher and learners lead to the perpetuation of the assumed roles for both learners and teacher that according to Freire (1970) are in deed the reflections of the colonialist and oppressive nature of the society. Moreover, teacher confuses the authority of knowledge with the authority of his or her professional authority which is in contrast with learners' freedom.

Critical pedagogy or libratory education, on the other hand, revolves around an anti-authoritarian and interactive approach which assumes an equal relation between learners and teacher. The teacher is no longer merely the one who teaches, but the one who is himself/herself taught in dialogue with the students, who in turn while being taught also, teaches (Freire, 1993).

Based on this approach, teachers and learners' dialogical relations can shape and reshape the roles. They are jointly in charge of a process in which all grow. The ways in which teachers perform their roles and the ways in which the whole environment of the class contributes to the transformational process that learners bear in order to be emancipated from society's negative labels and empowered to take control of their academic, social, political and economical destinies. In this process, authority no longer functions against freedom but must be on the side of freedom.

It seems to be really unlikely that Iranian English teachers who have long been accustomed to possessing the absolute authority of traditional classes as the main source of knowledge and information can modestly quit their presumed roles at the cost of applying an anonymous innovative approach. Actually, these roles and unequal relations have been so profoundly ingrained in the texture of Iranian educational system that any violation from these taken-for-granted roles sounds weird and unusual. Hence, all the learners unquestioningly and submissively accept their roles as something true and unchangeable. Thus, this trend incessantly strengthens and legitimates the atmosphere of silencing, oppression and the maintenance of the status quo that in turn are in lieu of the existing banking system of education. The following statements reveal the respective theme:

"Teachers are in charge of their classes. They should be able to efficiently manage and control the classes. They have to decide what or how to do the job. So students should listen to them carefully, and do their assignment as they are instructed. Teachers are the source of information who can guarantee learners' success. Students just depend on teachers as the main source of information because there is not enough explanation for some vocabulary and grammatical items in the book".

\section{F. Absence of Culture of Critical Thinking in Education}

According to Burbules and Burk (1999), over the past two decades, critical thinking and CP are considered to be two literatures which have shaped much of the writing in the educational foundations. In deed, critical thinking shares some common concerns with CP in that they both invoke the term "critical" as a valued educational goal. Critical thinking advocates believe that all the people need to be better critical thinkers and that critical thinking could have a general humanizing effect across all social groups and classes. The authors of both literatures would argue that by helping people become more critical in thought and action, minded educators can progressively assist the process of liberating learners to see the world as it is and to act up on social injustices. Furthermore, education in this sense can increase freedom and enlarge the scope of human possibilities.

Teachers are, thus, assumed to provide students with skills and knowledge necessary for them to expand their capacities both to question deep-seated assumptions and myths that legislate the most archaic and disempowering social practices and to take responsibility for intervening the world they inhibit (Mclaren \& Kincheloe, 2007). Through CP and critical thinking, educators can also make learners react toward institutionalized functions and educational institutions to raise questions about inequalities of power and about the belief systems which have been so internalized that the individuals abandon any questioning regarding their legitimacy.

In sum, as Burbules and Burk (1999) claim, in the language of critical pedagogy, a critical person is the one who is empowered to seek justice, to seek emancipation. So not only is the critical person adroit at recognizing injustice but, 
for critical pedagogy, that person is also moved to change it. In this sense, critical thinking lets people be more discerning in recognizing faulty arguments, hasty generalizations, and assertions lacking evidence, truth claims based on unreliable authority, ambiguous or obscure concepts, and so forth. It means that the people are required to learn how to express and criticize the logic of arguments that underpin their every day activities.

With respect to what was mentioned, it seems to be a futile and unwise effort to apply $\mathrm{CP}$ without any consideration of the necessity of creating the culture of critique and critical thinking among learners and teachers. In Iranian educational settings, criticizing has not yet appropriately evolved and is necessarily avoided since the culture of silencing is so commonplace that any critique in education counts as an unruly and unmanageable behavior which should be reprimanded. So this issue also deserves serious attention from language teachers in advance of taking any action. A teacher expressed his concern as below:

"I don't see any necessity to teach my students critically or make them think or study critically. In our educational system or even in our community and culture there is no room for critiques. The students are not culturally rich enough to criticize the text or material they are learning in class".

\section{G. Inefficiency of Pre-service and In-service Classes for English Teachers}

The most efficient means of cultivating teachers' academic awareness is through pre-service and in-service teacher training courses, which should be organized to enhance teachers' professional abilities (Hui, 1994). Throughout the world, teacher training programs are efficiently targeted at the service of teachers to update their professional knowledge of ELT and to provide them with the fruitful pedagogical practices, contemporary language learning theories and practical considerations of language learning classrooms.

However, what really matters in the in-service classes of ministry of education in Iran, is nothing but the provision of linguistic and grammatical knowledge aiming at the improvement of teachers' professional knowledge. I myself spent more than 300 hours of participating in the so-called "in-service classes" through which the instructors mentioned some grammatical points and structures leading to the subsequent discussion over formality or informality and their usage in American or British English and etc. While the educational system in Iran centers irrationally on the development of language knowledge and is even incapable of proceeding toward learner-centered approaches, life long professional development and teacher autonomy, thinking about an anonymous approach like critical pedagogy is beyond our expectations. As one of the teachers wisely referred to this fact:

"To be frank, we have participated hundreds of hours in in-service classes, but no new material or innovative issues have been introduced to us. The same instructors are in charge of these classes and they work on the same material they did before. This bitter fact has discouraged many of us and we have such a negative feedback toward these useless classes. If we were not obliged to take part in those in-service classes, the majority of us would never ever did. When you see nothing valuable, or useful to our career it does not seem logical to waste time on it".

\section{H. Culturally and Politically Inappropriate for our Education}

One teacher participating in the project mentioned another problem which is worth quoting here:

"We live in a traditional community dominated by rituals. The texts books are generally prepared based on these rules and principles. So not only the students but the teachers also have no right to criticize those rules or principles to cross the red line; otherwise they may lose their jobs. So teachers do their best to avoid speaking about or discussing the issues that might be politically or religiously misinterpreted".

Have those who theoretically developed the corner stones and principles of CP realized the limitations of moving from theory to practice in other societies with different traditions and cultures? Is it worth for teachers taking risks to be agents of social change at the cost of losing jobs or professional positions?

According to Sadeghi and Ketabi (2009), most teachers show no interest in politics and politically controversial issues. It is, indeed, considered to be something taboo which might endanger their job positions, personal and professional lives. It does not mean teachers be politically negligent and retrieve themselves from political projects. Rather, we should take into account the stakes for teachers in such an effort. In this regard, a note of caution seems appropriate in that according to Aliakbari and Allahmoradi (2012), critical pedagogy and its principles can be infused into the Iranian educational context provided that it does not contradict its culture and tradition. Thus, every teacher should behave vigilantly towards politically and challenging issues so as not to be underprivileged in such a risk.

\section{CONCLUSION}

Critical approach as a new approach which has a particular focus on teaching English as a sociopolitical enterprise connected to learners' lived experiences in the wider community has immensely influenced the field of ELT in various educational contexts throughout the world. In fact, it has also particularly contributed to the process of transforming both teacher and students to become social agents to act upon inequalities in the society. Moreover, education can better evolve through dialogical exchanges among teacher and students concentrating on the issues related to their sociopolitical contexts. However, in order to appropriately and feasibly move from theory to practice in an EFL context, I do suggest that taking necessarily its associated problems and constraints into account be significant for the intellectuals in advance of attempting to bring about any social transformation. This study was in deed an attempt to 
throw more light on the appropriacy of $\mathrm{CP}$ and the probable problems, concerns and limitations of its applicability in educational system of Iran. Through the use of a multi-method approach including observation, semi-structured interview and dialogic conversation, a crystal clear picture of the themes was derived. The respective themes which are culturally and socially bound to the educational context of Iran precisely reflect what teachers as intellectuals might face in such an EFL context. Thus, it is recommended that teachers should cautiously behave in this regard and meticulously consider all the possible impediments. Surely, if they evaluate the pros and cons of such an approach before application, undoubtedly, they can feasibly cope with any probable problems at the time of its use.

\section{REFERENCES}

[1] Akbari, R. (2008a). Postmethod discourses and practice. TESOL Quarterly 42.2, 641-652.

[2] Akbari, R. (2008b). Transforming lives: Introducing critical pedagogy into ELT classrooms. ELT Journal 62.3, $276-283$.

[3] Aliakbari, M. \& N. Allahmoradi (2012). On Iranian school teachers' perceptions on the principle of critical pedagogy. International Journal of Critical Pedagogy 4.1, 154-171.

[4] Benesch, S. (2001). Critical English for academic purposes: Theory, politics and practice. Mahwah, NJ: Lawrence Erlbaum Associates.

[5] Burbules, N.C. \& R. Burk (1999). Critical thinking and critical pedagogy: Relations, differences and limits. In T. S. Popkwitz, \& L. Fendler (eds.), Critical theories in education: Changing terrains of knowledge and politics. NY: Routledge, 45-66.

[6] Canagarajah, A. S. (1999). Revisiting linguistic imperialism in English teaching. Oxford, England: Oxford University Press.

[7] Canagarajah, S. (2002). Reconstructing local knowledge. Journal of Language, Identity and Education 1, $234-259$.

[8] Crookes, G. (2009). Values, philosophies, and beliefs in TESOL: Making a Statement. Cambridge: Cambridge University Press.

[9] Davari, H., A. Iranmehr \& S. M. Erfani (2012). A survey on the Iranians' ELT community's attitudes to critical pedagogy. English Language Teaching 5.2, 101-111.

[10] Davis, K.A. \& E. Skilton-Sylvester (2004). Looking back, taking stock, moving forward: Investigating gender in TESOL. TESOL Quarterly38.3, 381-404.

[11] Eisner, E. W. (2002). The arts of the creation of mind. New Haven: Yale University.

[12] Fairclough, N. (1995). Discourse analysis: The critical study of language. London: Longman.

[13] Freire, P. (1970). Pedagogy of the oppressed. NewYork: Continuum.

[14] Freire, P. (1993). Pedagogy of the oppressed. NewYork: Continuum.

[15] Freire, P. \& D. Macedo (1987). Literacy: Reading the word and world. Westport, CT: Bergin \& Gravery Publishing.

[16] Giroux, H. A. (1992). Border crossings: Cultural workers and the politics of education. NewYork, NY: Routledge.

[17] Gur-ze'ev, I. (1998). Toward a nonrepressive critical pedagogy. Educational theory 48.4, 463- 486.

[18] Heras, A. I. (1999). Taking action with family and community members: Critical pedagogy as a framework for educational change. In Z. Cline \& J. Necochea (eds.), Advances in confluent education. Stanford, CT: JAI Press.

[19] Hui, L. (1997). New bottles, old wine: Communicative language teaching in China. English Teaching Forum 35.4, 34-41.

[20] Kanpol, B. (1998).Critical pedagogy for beginning teachers: The movement from despair to hope. Retrieved from http://www.wmc.edu/academics /library/pub/jcp/issuell-1/kanpol.html (accessed 4/8/2008).

[21] Kincheloe, J. L. (1998). Critical research in science education. In B. Fraser \& K. Tobin (eds.) International Handbook of Science Education (part 2). Boston: Kluwer.

[22] Kincheloe, J. L. (2004). Critical pedagogy. NewYork: Peter Lang.

[23] Kincheloe, J. L. (2005). Critical constructivism. NewYork: Peter Lang.

[24] Kincheloe, J. L. (2007). Critical pedagogy in the twenty-first century: Evolution for survival. In P. Mclaren \& J.L. Kincheloe (eds.), critical pedagogy: Where are we now? NewYork: Peter Lang.

[25] Kumaravadivelu, B. (2006). TESOL methods: Changing tracks, challenging trends. TESOL Quarterly, 40 .1, 59-61.

[26] Lather, P. (1998). Critical pedagogy and its complicities: A praxis of stuck places. Educational Theory, 48.4, 487-497.

[27] Luke, A. (1988). Literacy, textbooks, and ideology. London, England: Falmer.

[28] Markee, N. (2002). Language in development: Questions of theory, questions of practice. TESOL Quarterly 36.3, $265-274$.

[29] Mclaren, P. (1989). Life in schools: An introduction to critical pedagogy in the foundations of education. White Plains, NY: Longman.

[30] Mclaren, P. (2000). Paulo Freire's pedagogy of possibility. In S. Steiner, H. Frank, P. Mclaren \& R. Bahruth (eds.), Freirean pedagogy, praxis and possibilities: Projects for the new millennium. NewYork: Falmer Press, 1-21.

[31] Mclaren, P. (2003). Life in schools: An introduction to critical pedagogy in the social foundations of education (4 ${ }^{\text {th }}$ edn.). NewYork: Falmer Press.

[32] Mclaren, P. (2007). Life in schools: An introduction to critical pedagogy in the foundations of education (5 ${ }^{\text {th }}$ edn.). Boston, MA: Pearson.

[33] Medgyes, P. (2001). When the teacher is in a non-native speaker. In M. Celcie-Murcia (ed.), Teaching English as a second or foreign language (3rd edn.). Boston: Heinle \& Heinle, 415-427.

[34] Morgan, B. (1998). The ESL classroom: Teaching, critical practice, and community. Toronto, Ontario, Canada: Toronto University Press.

[35] Noroozisiam, E. \& S. M. A. Soozandehfar (2011). Teaching through critical pedagogy: Problems and attitudes. Theory and Practice in Language Studies 1.9, 1240-1244.

[36] Norton, B. (1997). Language and identity, and the ownership of English. TESOL Quarterly 31.3, 409-429.

[37] Norton, B., \& K. Toohey (eds.) (2004). Critical pedagogies and language learning. Cambridge, England: Cambridge University Press.

[38] Palmer, J. \& K. Emmons (2004). Critical pedagogy: An overview. Retrieved from http://www.case.edu/artsci/engl/emmons/writing/pedagogy/critical.pdf (accessed 21/5/2012). 
[39] Okazaki, T. (2005). Critical consciousness and critical language. Second Language studies 23.2, 174-202.

[40] Pennycook, A. (1999). Introduction: Critical approaches to TESOL. TESOL Quarterly 33.3, 329-348.

[41] Pennycook, A. (2001). Critical applied linguistics: A critical introduction. Mahwah, NJ: Lawrence Erlbaum.

[42] Ramanathan, V. (2002). The Politics of TESOL Education: Writing, knowledge, critical pedagogy. NewYork: Routledge Falmer.

[43] Rashidi, R. \& F. Safari (2011). A model for EFL materials development within the framework of critical pedagogy. English Language Teaching 4.2, 250-59.

[44] Richards, Jack C. (2011). Competence and performance in language teaching. New York: Cambridge University Press.

[45] Sadeghi, S. \& S. Ketabi (2009). From liberal ostrichism to transformative intellectuals: An alternative role for Iranian critical pedagogues. Journal of English Language Teacher Education and Development 12, 52-60.

[46] Simon, R. (1992). Teaching against the grain: Texts for pedagogy of possibility. New York: Bergin and Garvey.

[47] Zacharias, N.T. (2003). A survey of tertiary teachers' beliefs about English language teaching in Indonesia with regard to the role of English as a global language. Unpublished M.A. thesis, Thailand University.

Parvin Safari received her B.A. in TEFL from Shiraz University. She got her M.A. in TEFL from Yazd University. She is a teacher educator in Teacher Education College of Yazd, Iran, and currently teaching English in Iranian schools in Kuwait. She has presented some papers in different international conferences. Her main areas of interest are: critical applied linguistics, teacher education, and discourse analysis.

Mohammad R. Pourhashemi received his B.A. in TEFL from Shiraz University. He got his M.A. from Yazd University. He is a teacher educator in Teacher Education College of Yazd, Iran, and currently teaching English in Iranian schools in Kuwait. He has published some papers in Iranian journals. His areas of interest are: applied linguistics and teaching methodology. 